$$
\begin{array}{r|l}
\text { Jurnal Sains Komputer dan Teknologi Informasi } & \text { Page } \\
\text { E-1SSN: 2655-7460. Volume 2 Issue 2, Mei 2020 } & 36-43
\end{array}
$$

\title{
PEMODELAN BASIS DATA DENGAN PENDEKATAN MODEL DATA BERORIENTASI OBJEK PADA NATIVE APPS LOKASI TEMPAT IBADAH DI KOTA PALANGKA RAYA
}

\author{
Rio Irawan ${ }^{1}$, Rommi Kaestria ${ }^{2}$ \\ Manajemen Pendidikan Islam - Institut Agama Islam Negeri (IAIN) Palangka Raya, Jl. G. Obos Kompleks \\ Islamik Center, Palangka Raya, Kalimantan Tengah, 73112 \\ Sistem Informasi - STMIK Palangkaraya, Jl. G. Obos No. 114, Palangka Raya, Kalimantan Tengah² \\ Email : rioirawan@iain-palangkaraya.ac.id ${ }^{1}$ \\ Email : rokafordev@gmail.com ${ }^{2}$
}

\begin{abstract}
ABSTRAK
Pemodelan basis dengan pendekatan model data berorientasi objek dibuat untuk menghasilkan sebuah desain basis data beroritentasi objek dalam pengembagnan native apps lokasi tempat ibadah di Kota Palangka Raya. Perkembagnan native apps yang begitu pesat baik pada platform android ataupun IOS akan memberikan tantangan tersendiri bagi pengembang untuk menghasilkan sebuah aplikasi yang mendekati atau semaksimal mungkin sesuai dengan kondisi real. Dengan model data berorientasi objek ini, mempermudah dala melakukan analisis permasalahan sebab akan analogikan menjadi sebuah objek, kemudian objek tersebut akan dibuat yang mempunyai sifat atau ciri khas yang berbeda antar kelas. Pemodelan model data berorientasi objek menggunakan Unified Modelling Language (UML) dengan menggunakan Class Diagram. Hasil dari penelitian ini berupa desain pemodelan basis data agar mempermudah pengembang aplikasi pada saat pengembangan native apps yang umumnya dikembangkan dengan permograman beroritenasi objek.
\end{abstract}

Kata kunci : Pemodelan Basis Data, Model Data Berorientasi Objek, Native Apps

\begin{abstract}
Base modeling with an object-oriented data model approach is made to produce an object-oriented database design in developing native apps for places of worship in Palangka Raya City. The rapid development of native apps on both the Android and iOS platforms will provide a challenge for developers to produce an application that is as close or as close as possible to real conditions. With this object-oriented data model, it is easier to do problem analysis because it will be analogous to an object, then the object will be created that has different characteristics or characteristics between classes. Object-oriented data modeling using Unified Modeling Language (UML) using Class Diagrams. The results of this study are in the form of database modeling design to facilitate application developers when developing native apps which are generally developed with object-oriented programming
\end{abstract}

Keywords : Database Modeling, Object-Oriented Data Model, Native Apps

\section{PENDAHULUAN}

Teknologi informasi memilki peran yang sangat besar terhadap arus informasi sekarang ini, dalam segala aspek bidang, maupun dalam kegiatan rutin yang dilakukan seharihari. Teknologi informasi erat kaitannya dengan data, dari yang awalnya berupa raw data atau data mentah kemudian diolah menjadi sebuah informasi akhir yang bermanfaat bagi pengguna. Semakin banyak data yang tersimpan dalam sebuah sistem tentunya akan semakin banyak pula informasi yang dapat diolah dan dihasilkan yang disesuikan dengan kebutuhan informasi yang diinginkan.
Pengolahan raw data dilakukan dengan memanfaatkan Database Management System (DBMS) yang dibuat agar memudahkan dan mengefisiensikan pemasukan, pengeditan, penghapusan dan pengambilan informasi terhadap database [4]. Manfaat dan kelebihan melakukan penyimpanan data dalam DBMS yaitu dalam segi performance, integritas, independesni, sentralisasi, dan security. [4]

Dengan perkembangan teknologi yang semakin pesat mendorong serta kebutuhan akan informasi yang ceoat dan tepat pula, untuk itu diperlukan desain basis data yang mampu menunjang kebutuhan informasi yang sering berubah-ubah setiap waktu. Dengan memanfaatkan pendekatan berbasis objek, sebuah kebutuhan data akan dianalisis dan dibagi 
Rio Irawan \& Rommi Kaestria. Pemodelan Basis Data dengan Pendekatan Model Data 2020
Berorientasi Objek pada Native Apps Lokasi Tempat lbadah di Kota Palangka Raya

kedalam objek-objek tertentu yang terpisah dari objek lainnya, sehingga mudah dalam proses pemodelannya sesuai dengan permasalahan yang ditemukan yang kemudian akan diterjemahkan ke dalam sebuah database.

Native apps merupakan sebuah aplikasi yang umumnya diperuntukkan bagi pengguna smartphone, yang dikembangkan dengan menggunakan Bahasa pemerograman tertentu yang spesifik untuk plalfform tertentu, misalnya smartphone berbasis Android atau IOS. Perkembangan dan pegembangan native apps yang dilakukan oleh para developer yang banyak dikembangkan adalah aplikasi berbasis lokasi yang berguna sebagai petunjuk arah kesuatu daerah atau objek tertentu dengan memanfaatkan layanan GPS dan peta digital yang dimiliki oleh beberapa penyedia layanan, misalnya Google Maps, Here Maps dan lain sebagainya dengan cara melakukan sinkronisasi data antara sistem yang dikembangkan dengan Application Programming Interface (API) yang dimiliki oleh penyedia layanan peta digital.

Detail lokasi, terutama dalam hal ini longitude dan latitude merupakan indikator yang sangat berpengaruh terhadap aplikasi berbasis lokasi. Dengan data longitude dan latitude yang tepat maka sistem akan menampilkan data lokasi yang sesuai, pentunjuk arah yang tepat dan detail-detail informasi lainnya. Untuk itu, diperlukannya sebuah pemodelan database yang baik sehingga menghasilkan sistem baik pula, yaitu sistem yang tepat dalam memberikan informasi lokasi tempat ibadah yang di-request oleh pengguna melalui aplikasi.

Fokus pada penelitian ini akan memberikan gambaran mengenai basis data yang disusun atau dirancang dengan melakukan pendekatan berbasis objek dengan studi kasus lokasi tempat ibadah yang terdapat di Kota Palangka Raya, Provinsi Kalimantan Tengah.

\section{TINJAUAN PUSATAKA}

Beberapa rujukan penelitian terdaulu yang dijadikan dasar pada penelitian ini yaitu sebagai berikut:

a. Penelitian dengan judul Implementasi Location Based Services (Ibs) Kantor Pemerintahan Kota (studi Kasus : Kota Palangka Raya, Provinsi Kalimantan Tengah, Indonesia). Pada penelitian ini menjelaskan mengeai implemantasi aplikasi berbasis lokasi yang memapu memberikan detail informasi mulai dari jarak tempuh, estimasi waktu, petunjuk arah, rute dan lain sebagainya.

b. Penelitian dengan judul Pemodelan Basis Data Akademik Universitas XYZ Menggunakan Pendekatan Objek.. penelitian ini menghasilkan desain basis data akademik untuk menghubungkan antara spesifikasi kebutuhan dan implementasi yang akan membantu pihak pengembang sistem.

c. Penelitian dengan judul Perancangan Databae Point of Sales Apotek Dengan Menerapkan Model Data Relasional. Pada penelitian ini desain database dengan menggunakan metode Database Life Cycle
(DBLC) yaitu desain konseptual, desain logikal dan desain fisikal.

\subsection{Landasan Teori} beriku :

Teori pendukung dalam penelitian ini yaitu sebagai

\subsubsection{Basis Data}

Basis data terdidi dari 2 kata, yaitu basis dan data. Basis dapat diartikan sebagai markas, Gudang, tempat berkumpul. Sedangkan data adalah fakta yang mewakili suatu objek sepeprti manusia, barang, hewan, peristiwa, keadaan dan sebagainya, yang direkam dala mbetnuk angka, huruf, symbol, teks gambar, bunyi atau kombinasinya. Basis data sendiri dapat di definisikan dalam sejumlah sudut pandang seperti : [5]

a. Himpunan kelompok data yang saling berhubungan yang diorganisasi sedimikian rupa agar dapat dimanfaatkan Kembali dengan cepat dan mudah.

b. Kumpulan data yang saling berhubungan yang disimpan secara bersama sedemikian rupa dan tanpa pengulangan (redundansi), untuk memenuhi berbagai kebutuhan.

c. Kumpulan file yang saling berhubungan yang disimpan dalam media penyimpanan elektroniks.

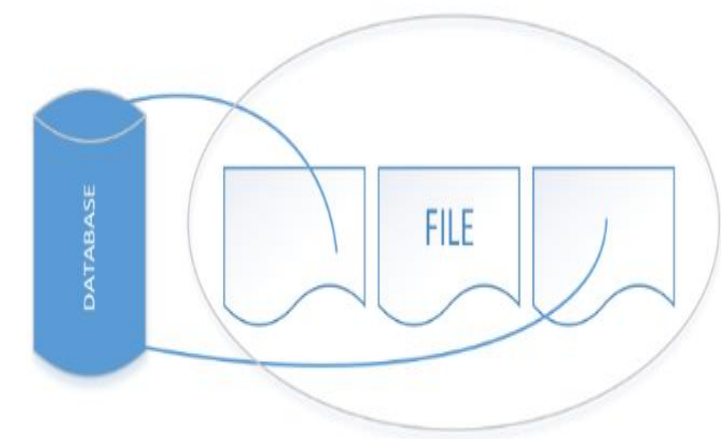

Gambar 1. Ilustrasi Basis Data [5]

\subsubsection{Model Data Berorientasi Objek}

Menurut Connoly dan Begg dalam [2] Basis data berbasis objek terdiri dari Object-Oriented Data Model (OODM), Object-Oriented Data Base (OODB) dan Object-Oriented DBMS (OODBMS). OODM adalah suatu model data logika yang menangkap semantik dari objek yang didukung oleh pemrograman berbasis objek sedangkan OODB adalah sekelompok objek persistent dan sharable yang didefinisikan OODM, dan OODBMS merupakan manajer dari OODB.

Menurut [5], manifesto OODBMS yaitu mendukung objek objek kompleks, mendukung identitas objek, memungkinkan objek dikapsulkan, mendukung tipe atau kelas, mendukung pewarisan, menghindari tehnik binding yang dini dan dapat mengingat lokasi data. 


$$
\begin{array}{r|l}
\text { Jurnal Sains Komputer dan Teknologi Informasi } & \text { Page } \\
\text { E-ISSN: 2655-7460. Volume 2 Issue 2, Mei 2020 } & 36-43
\end{array}
$$

Kelemahan OODBMS:

a. Kemungkinan korupsi basis data

b. Kekurangan dan perluasan logik

c. OODB lebih sulit dimengerti.

d. Dibutuhkan orang yang benar-benar menguasai OODB.

Keunggulan OODBMS:

a. Fitur fitur lanjut

b. Sistem tipe yang seragam

c. Dapat menyimpan kelas dengan jumlah banyak

d. Dapat mengatasi data yang interrelated dan kompleks

\subsubsection{Native Apps}

Purely Native apps - these apps are written in a device-specific language, using a device-specific programming interface: objective-C for iPhone apps or Java for Android apps. Native apps can access all the capabilities of the device and can take many forms, from simple utility to advanced 3-D games. [6]

Aplikasi native adalah aplikasi yang dibangun dengan bahasa pemrograman yang spesifik untuk platform tertentu. Contoh populernya yakni penggunaan bahasa pemrograman Objective-C atau Swift untuk platform iOS (Apple). Adapun platform Android yang menggunakan bahasa pemrograman Java.[7]

\subsubsection{Location Based Service}

Sebuah layanan berbasis lokasi adalah layanan informasi atau hiburan yang dapat diakses dengan perangkat mobile melalui jaringan selular. Sistem Layanan Berbasis Lokasi,atau lebih dikenal dengan Location-Based Services (LBS), menggabungkan antara proses dari layanan mobile dengan posisi geografis dari penggunanya. Posisi target, dimana sebuah target bisa jadi adalah pengguna Location- Based Services itu sendiri atau entitas lain yang tergabung dalam suatu layanan. Location Provider Menyediakan teknologi pencarian lokasi yang berasal dari perangkat. API Location berhubungan dengan data Global Positioning System (GPS) dan data lokasi real-time.[1]

Menurut Manav dan Shukla dalam [1] Unsur utama dari LBS yaitu location manager (API Maps) dan location provider (API Location). Sedangkan komponen LBS menurut Pankti, Jain dan Shakwala dalam [1] yaitu piranti mobile, jaringan komunikasi, komponen positioning, penyedia layanan dan aplikasi dan penyedia data dan konten

\subsubsection{Unified Modeling Language (UML)}

Unified Modeling Language (UML) digunakan untuk mendefenisikan requirement, membuat analisis dan desain, serta menggambarkan arsitektur dalam pemrograman berorientasi objek. [1]
Unified Modeling Language selanjutnya disebut UML adalah sebuah teknik pengembangan sistem yang menggunakan bahasa grafis sebagai alat untuk pendokumentasian dan melakukan spesifikasi pada sistem.[8]

\section{METODE PENELITIAN}

Tahapan yang dilakukan dalam melakukan penelitian ini untuk menghasilkan desain atau model basis data lokasi tempat ibadah di Kota Palangka Raya dengan melakukan studi pustaka terhadap penelitian-penelitian yang relevan terhadap studi kasus yang diteliti serta melakukan observasi terhadap beberapa aplikasi native berbasis lokasi dalam proses pengumpulan data.

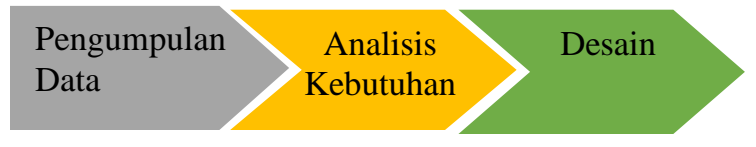

Gambar 2. Rancangan Penelitian

Berdasarkan hasil pengumpulan data, dianalisis hingga menghasilkan atau mendefinisikan kelas-kelas yang akan digunakan untuk melakukan proses perancangan basis data hingga pada akhirnya dilakukan implementasi pada saat pengembangan perangkat lunak atau aplikasi native.

\section{HASIL DAN PEMBAHASAN}

Setelah data diperoleh dan telah dilakukan analisis kebutuhan, maka proses selanjtunya adalah proses desain atau pemodelan basis data dengan pendekatan berorientasi objek.

\subsection{Pemetaan Kelas}

Berdasarkan hasil analisis, dilakukan pemetaan kelas yang akan digunakan pada perancangan model objek. Daftar kelas yang dipetakan terlihat pada tabel 1 .

Tabel 1. Pemetaan Kelas

\begin{tabular}{|c|l|l|}
\hline No & \multicolumn{1}{|c|}{ Nama Kelas } & \multicolumn{1}{|c|}{ Keterangan } \\
\hline 1 & Tempat_ibadah & $\begin{array}{l}\text { menggambarkan property } \\
\text { yang dimiliki oleh tempat } \\
\text { ibadah }\end{array}$ \\
\hline 2 & Kategori & $\begin{array}{l}\text { Menggambarkan property } \\
\text { dari kategori tempat } \\
\text { ibadah }\end{array}$ \\
\hline 3 & Detail & $\begin{array}{l}\text { Informasi detail tempat } \\
\text { ibadah }\end{array}$ \\
\hline
\end{tabular}

Berdasarkan pada tabel 1, maka kelas yang telah dipetakan akan didesain seperti berikut ini. 
Rio Irawan \& Rommi Kaestría. Pemodelan Basis Data dengan Pendekatan Model Data 2020

Berorientasi Objek pada Native Apps Lokasi Tempat lbadah di Kota Palangka Raya
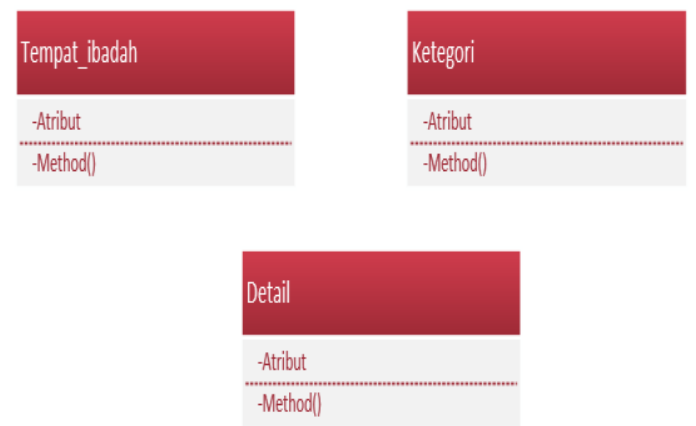

Gambar 3. Desain Pemetaan Kelas

\subsection{Pemetaan Atribut}

Dari hasil pemetaan kelas, selanjutnya masin-masing kelas akan diisi dengan atribut-atribut untuk menjelaskan lebih detail tentang sifat atau nilai dari kelas seperti pada tabel-tabel berikut ini.

Tabel 2. Pemetaan Atribut Kelas Tempat Ibadah

\begin{tabular}{|l|l|l|l|}
\hline No & Nama Atribut & \multicolumn{1}{|c|}{$\begin{array}{c}\text { Nilai } \\
\text { Atribut }\end{array}$} & \multicolumn{1}{|c|}{ Keterangan } \\
\hline 1 & Id & Int & $\begin{array}{l}\text { Indikator tempat } \\
\text { ibadah }\end{array}$ \\
\hline 2 & Nama & Varchar & $\begin{array}{l}\text { Nama tempat } \\
\text { ibadah }\end{array}$ \\
\hline 3 & Agama & Varchar & $\begin{array}{l}\text { Agama penggun } \\
\text { tempat ibadah }\end{array}$ \\
\hline 4 & Latitude & Varchar & $\begin{array}{l}\text { Nilai latitude tempat } \\
\text { ibadah longitude }\end{array}$ \\
\hline 5 & Longitude & Varchar & $\begin{array}{l}\text { Nilai lai lempat ibadah } \\
\text { tempan }\end{array}$ \\
\hline
\end{tabular}

Hasil dari pemetaan atribut pada kelas Tempat_ibadah dapat digambarkan seperti berikut.

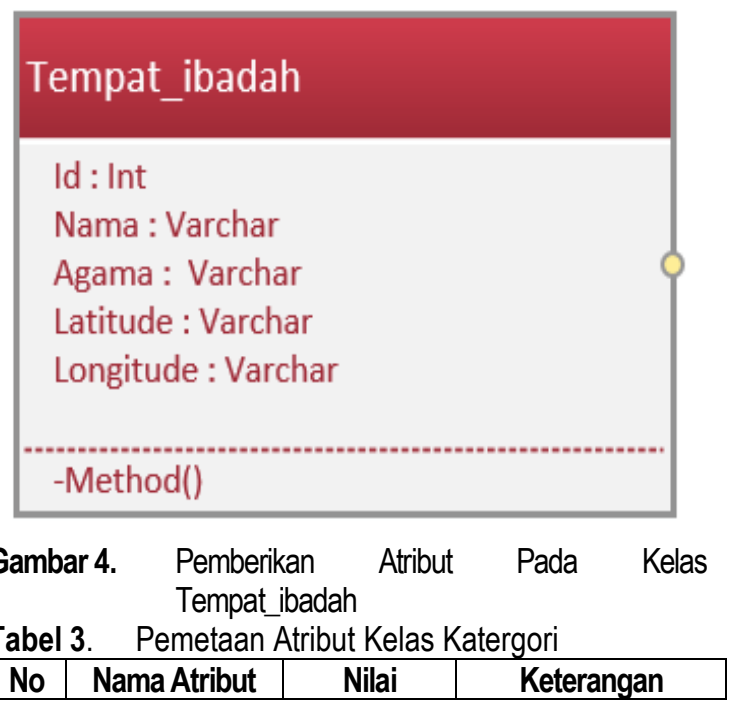

\begin{tabular}{|l|l|l|l|}
\hline 1 & Id & Atribut & \\
\hline 2 & Nama & Varchar & $\begin{array}{l}\text { Indikator kategori } \\
\text { tempat ibadah }\end{array}$ \\
\hline $\begin{array}{l}\text { Nama kategori } \\
\text { tempat ibadah }\end{array}$ \\
\hline
\end{tabular}

Hasil dari pemetaan atribut pada kleas Kategori dapat digambarkan seperti berikut.

\section{Ketegori}

$$
\begin{aligned}
& \text { Id : Int } \\
& \text { Nama : Varchar } \\
& \text {-Method() }
\end{aligned}
$$

Gambar 5. Pemberikan Atribut Pada Kelas Kategori

Tabel 4. Pemetaan Atribut Kelas Detail

\begin{tabular}{|l|l|l|l|}
\hline No & Nama Atribut & $\begin{array}{c}\text { Nilai } \\
\text { Atribut }\end{array}$ & \multicolumn{1}{|c|}{ Keterangan } \\
\hline 1 & Id & Int & $\begin{array}{l}\text { Indikator detail } \\
\text { tempat ibadah }\end{array}$ \\
\hline 2 & Alamat & Text & $\begin{array}{l}\text { Alamat tempat } \\
\text { ibadah }\end{array}$ \\
\hline 3 & Kelurahan & Varchar & $\begin{array}{l}\text { Nama kelurahan } \\
\text { tempat ibadah }\end{array}$ \\
\hline 4 & Kecamatan & Varchar & $\begin{array}{l}\text { Nama kecamatan } \\
\text { tempat ibadah }\end{array}$ \\
\hline 5 & Fasilitas & Text & $\begin{array}{l}\text { Vasilitas yang ada } \\
\text { ditempat ibadah }\end{array}$ \\
\hline 6 & Keterangan & Text & $\begin{array}{l}\text { Informasi tempat } \\
\text { ibadah lainnya }\end{array}$ \\
\hline 7 & Foto1 & Varchar & $\begin{array}{l}\text { Foto tempat ibadah } \\
\text { pertama }\end{array}$ \\
\hline 8 & Foto2 & Varchar & $\begin{array}{l}\text { Foto tempat ibadah } \\
\text { kedua }\end{array}$ \\
\hline
\end{tabular}

Hasil dari pemetaan atribut pada kelas Detail dapat digambarkan seperti berikut.

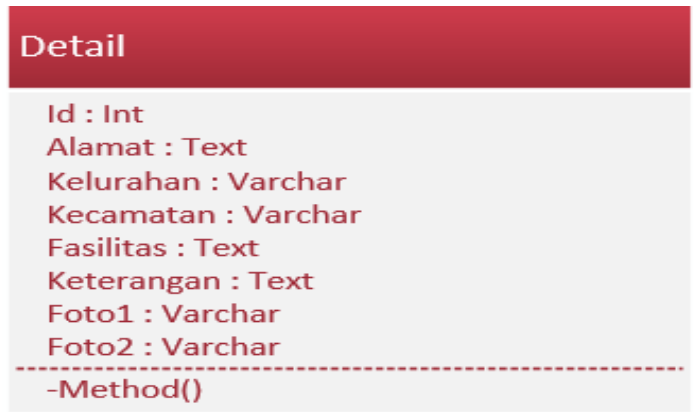

Gambar 6. Pemberikan Atribut Pada Kelas Detail 4.3 Pemetaan Metode/operasi 


$$
\begin{array}{r|l}
\text { Jurnal Sains Komputer dan Teknologi Informasi } & \text { Page } \\
\text { E-ISSN: 2655-7460. Volume 2 Issue 2, Mei 2020 } & 36-43
\end{array}
$$

Setelah kelas yang telah ditentukan diberikan atribut, berikutnya kelas akan diebrikan metode berikut dengan sifatnya seperti pada tabel berikut ini.

\begin{tabular}{|c|c|c|c|}
\hline No & Nama Metode & Sifat & Keterangan \\
\hline 1 & GetKategori() & + (Public) & $\begin{array}{l}\text { Memanggil } \\
\text { atau } \\
\text { menampilkan } \\
\text { data kategori } \\
\text { pada kelas } \\
\text { kategori }\end{array}$ \\
\hline 2 & AddData() & \# (Protected) & $\begin{array}{l}\text { Melakukan } \\
\text { penambahan } \\
\text { data tempat } \\
\text { ibadah }\end{array}$ \\
\hline 3 & UpdateData() & \# (Protected) & $\begin{array}{l}\text { Melakukan } \\
\text { proses } \\
\text { perubahan } \\
\text { data tempat } \\
\text { ibadah }\end{array}$ \\
\hline 4 & DeleteData() & \# (Protected) & $\begin{array}{l}\text { Menghapus } \\
\text { data tempat } \\
\text { ibadah }\end{array}$ \\
\hline 5 & GetData () & + (Public) & $\begin{array}{l}\text { Memanggil } \\
\text { atau } \\
\text { menampilkan } \\
\text { data tempat } \\
\text { ibadah }\end{array}$ \\
\hline 6 & GetDataSearch() & \# (Protected) & $\begin{array}{l}\text { Menampilkan } \\
\text { data tempat } \\
\text { ibadah } \\
\text { berdasarkan } \\
\text { hasil pencarian } \\
\text { nama tempat } \\
\text { ibadah }\end{array}$ \\
\hline 7 & GetDataFilter() & \# (Protected) & $\begin{array}{l}\text { Menampilkan } \\
\text { data tempat } \\
\text { ibadah } \\
\text { berdasarkan } \\
\text { filter data }\end{array}$ \\
\hline 8 & GetDetail() & + (Public) & $\begin{array}{l}\text { Memanggil } \\
\text { atau } \\
\text { menampilkan } \\
\text { detail tempat } \\
\text { ibadah pada } \\
\text { kelas detail }\end{array}$ \\
\hline
\end{tabular}

Tabel 5. Pemetaan Metode Kelas Tempat Ibadah

Hasil pemeteaan metode terhadap kleas Tempat_ibadah terlihat seperti pada gambar berikut ini.

\section{Tempat_ibadah}

\section{Id : Int}

Nama : Varchar

Agama : Varchar

Latitude : Varchar

Longitude : Varchar

+ GetKategori()

\#AddData()

\#UpdateData()

\#DeleteData()

+GetData()

\#GetDataSearch()

\#GetDataFilter()

+ GetDetail()

$\begin{array}{ll}\text { Gambar 7. } & \text { Pemberikan Metode Pada Kelas } \\ \text { Tempat_ibadah }\end{array}$

Tabel 6. Pemetaan Metode Kelas Kategori

\begin{tabular}{|l|l|l|l|}
\hline No & Nama Metode & \multicolumn{1}{|c|}{ Sifat } & \multicolumn{1}{|c|}{ Keterangan } \\
\hline 1 & GetKategori() & +(Public) & $\begin{array}{l}\text { Memanggil / } \\
\text { menampilkan } \\
\text { data kategori }\end{array}$ \\
\hline 2 & AddData() & \#(Protected) & $\begin{array}{l}\text { Melakukan } \\
\text { penambahan } \\
\text { data kategori } \\
\text { tempat ibadah }\end{array}$ \\
\hline 3 & UpdateData() & \#(Protected) & $\begin{array}{l}\text { Melakukan } \\
\text { proses } \\
\text { perubahan data } \\
\text { kategori } \\
\text { tempat ibadah }\end{array}$ \\
\hline 4 & DeleteData() & \#(Protected) & $\begin{array}{l}\text { Menghapus } \\
\text { data kategori } \\
\text { tempat ibadah }\end{array}$ \\
\hline
\end{tabular}

Hasil pemeteaan metode terhadap kelas Kategori terlihat seperti pada gambar berikut ini.

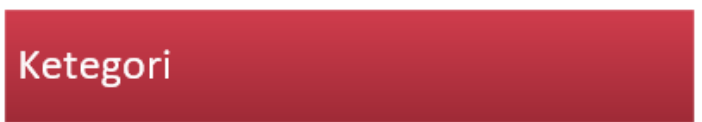

Id : Int

Nama : Varchar

+ GetKategori()

\# AddData()

\#UpadateData()

\#DeleteData() 
Rio Irawan \& Rommi Kaestria. Pemodelan Basis Data dengan Pendekatan Model Data 2020
Berorientasi Objek pada Native Apps Lokasi Tempat lbadah di Kota Palangka Raya

Gambar 8. Pemberikan Metode Pada Kelas Kategori

Tabel 7. Pemetaan Metode Kelas Detail

\begin{tabular}{|l|l|l|l|}
\hline No & Nama Metode & \multicolumn{1}{|c|}{ Sifat } & \multicolumn{1}{|c|}{ Keterangan } \\
\hline 1 & GetDetail () & + (Public) & $\begin{array}{l}\text { Memanggil } \\
\text { atau } \\
\text { menampilkan } \\
\text { data detail tepat } \\
\text { ibadah }\end{array}$ \\
\hline 2 & AddData() & \#(Protected) & $\begin{array}{l}\text { Melakukan } \\
\text { penambahan } \\
\text { data detail } \\
\text { tempat ibadah }\end{array}$ \\
\hline 3 & UpdateData) & \#(Protected) & $\begin{array}{l}\text { Melakukan } \\
\text { proses } \\
\text { perubahan data } \\
\text { detail tempat } \\
\text { ibadah }\end{array}$ \\
\hline 4 & DeleteData() & \#(Protected) & $\begin{array}{l}\text { Menghapus } \\
\text { data detail } \\
\text { tempat ibadah }\end{array}$ \\
\hline
\end{tabular}

Hasil pemeteaan metode terhadap kelas Detail terlihat seperti pada gambar berikut ini.

Detail
Id : Int
Alamat : Text
Kelurahan : Varchar
Kecamatan : Varchar
Fasilitas : Text
Keterangan : Text
Foto1 : Varchar
Foto2 : Varchar
+---:-----------------------------
\#AddData()
\#UpdateData()
\#DeleteData()

Gambar 9. Pemberikan Metode Pada Kelas Detail

\subsection{Model Objek}

Setelah kelas diberikan atribut dan metode, kemudian dilakukan integrasi dan implementasi dalam pembuatan basis data yang disesuaikan dengan kelas-kelas yang telah ditentukan. Maka akan terlihat gambaran hubungan antar kelas yang terjadi seperti gambar berikut ini.

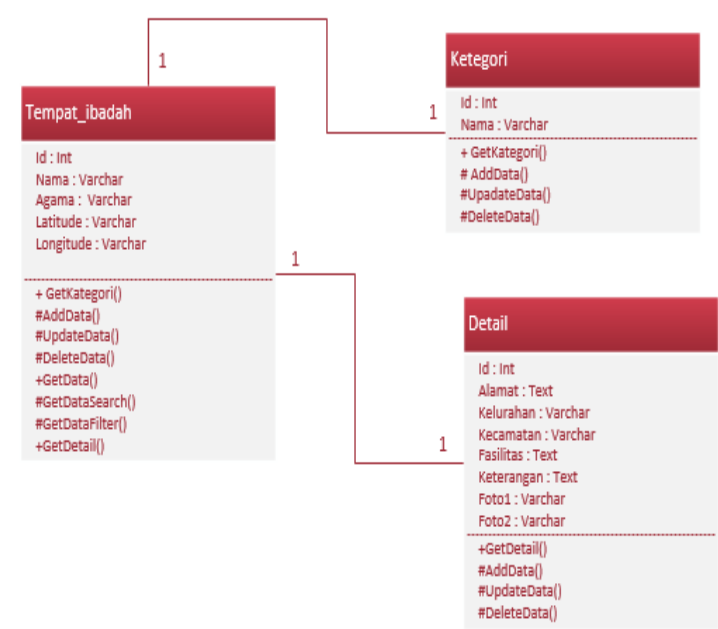

Gambar 10. Model Objek (Class Diagram)

\section{KESIMPULAN}

Pemodelan basis data dengan pendekatan model data berorientasi objek pada native apps lokasi tempat ibadah di Kota Palangka Raya dilakukan dengan melakukan analisa masalah kedalam sebuah objek, kemudian objek-objek tersebut akan dipecah menjadi beberapa kelas yang menunjukkan karakteristik kleas-kelas masing-masing.

Pemodelan basis data dengan pendekatan berbasis objek dibuat dengan tujuan memudahan pada saat pengembangan perangkat lunak, yang dikhusukan pula berorientasi objek. Selain itu, dengan menerapkan pemodelan ini memungkinkan memudahkan dalam tahap analisi, desain, implementasi dan pengujian perangkat lunak dalam hal ini native apps.

Desain pemodelan basis data ini dibuat untuk mempermudah dalam menganalisis kebutuhan fungsional dari native apps lokasi tempat ibadah di Kota Palangka Raya. Sehingga, diharapkan dengan hasil pemodelan ini native apps yang dikembagnkan mampu memberikan informasi yang akurat dan mempunyai kualitas informasi yang baik pula agar bermanfaat bagi pengguna.

\section{DAFTAR PUSTAKA}

[1] Irawan, Rio. "Implementasi Location Based Services (Ibs) Kantor Pemerintahan Kota (studi Kasus : Kota Palangka Raya, Provinsi Kalimantan Tengah, Indonesia)", FAHMA Journal Teknologi Informasi dan IImu Komputer, vol. 14, no. 2, 2016, pp. 35-56.

[2] Wulandari, Fera Tri. "Pemodelan Basis Data Akademik Universitas XYZ Menggunakan Pendekatan Objek". JITU : Journal Informatic Technology And Communication, vol. 3, no. 1, 2019, pp. 52-57. 


$$
\begin{array}{r|l}
\text { Jurnal Sains Komputer dan Teknologi Informasi } & \text { Page } \\
\text { E-1SSN: 2655-7460. Volume 2 Issue 2, Mei 2020 } & 36-43
\end{array}
$$

[3] Umar, Rusydi, dkk, "Perancangan Databae Point of Sales Apotek Dengan Menerapkan Model Data Relasional". Query: Jurnal Sistem Informasi, vol. 03. no. 2, 2019, pp. 33-41.

[4] Yanto, Robi, 2016. "Manajemen Basis Data Menggunakan MySQL". Yogyakarta: Deepublish.

[5] Hariyanto, B., 2004, "Sistem Manajemen Basisdata". Bandung: Informatika.

[6] Rodger, Richard, 2011. "Beginning Mobile Application Development in the Cloud". New Jersey, United States: Wiley.

[7] Pernama, Yana. 2016, "Ini Dia Perbedaan Aplikasi Native, Hybrid atau Web". https://www.codepolitan.com/apa-bedanya-aplikasinative-hybrid-dan-web, on 3 April 2020.

[8] Mulyani, Sri. 2016. "Metode Analisis dan Perancangan Sistem". Bandung: Abdi Sistematika 